\title{
Amar e escrita nos Fragmentos de um discurso amoroso, de Roland Barthes
}

\author{
Priscila Pesce Lopes de Oliveira" \\ Cid Ottoni Bylaardt**
}

\section{Resumo}

O presente artigo lê unidades de Fragmentos de um discurso amoroso, de Roland Barthes, esquadrinhando as relações que ali aparecem entre amar, escrita e língua, donde puxa fios de aspectos mais amplos do livro e da obra do autor. Lemos Fragmentos em rede com seus arredores escriturais, como diários e artigos, e vemos que a escrita ensaística, longe de abandonar reivindicações teóricas relativas a acepções de escrita, sujeito e outras bandeiras pelas quais Barthes bateu-se publicamente nos anos precedentes, pressupõe-nas e as integra. Nesse sentido, conforme o livro coloca em questão não apenas um objeto (o discurso amoroso), mas também o seu próprio fazer enquanto escrita que se quer amorosa, a prática de escrever é ali recolocada em outros termos: no interminável de uma ferida.

Palavras-chave: Roland Barthes; Fragmentos de um discurso amoroso; Escritura; Amor.

\section{Introdução}

Roland Barthes foi figura célebre do pensamento francês na segunda metade do século XX. Incomodado pelo que circula e escorre entre linguagem, significação e coletividades, Barthes indagou-se acerca de temas diversos, porém seu grande amor foi mesmo a literatura. A essa palavra (literatura) ele nem sempre foi fiel, tampouco às diferentes ciências e aos paradigmas dos quais se aproximou e distanciou ao longo dos anos. Tal mis-

\footnotetext{
* Doutora em Letras (2020) pela Universidade Federal do Ceará - UFC e pesquisadora da escrita barthesiana desde 2009. E-mail: priscilapesce@gmail.com Orcid: https://orcid. org/0000-0002-2073-5042

** Possui graduação em Letras e doutorado em Estudos Literários pela Universidade Federal de Minas Gerais, e pós-doutorado em Literatura Comparada pela Universidade de Coimbra, Portugal. É professor Associado IV de Literatura Brasileira da Universidade Federal do Ceará, com projeto de pesquisa denominado "Esvaziamento da História nas Literaturas Brasileira e Portuguesa Contemporâneas". Tem interesse particular em literatura contemporânea, brasileira e internacional, mas não só. Tem mais de uma centena de textos publicados sobre literatura e cultura brasileira e portuguesa, e orienta teses e dissertações. Escreve também poemas e romances. É músico amador (instrumentos: piano e viola), com interesse em música brasileira e internacional (clássica e erudita). É Bolsista de Produtividade em Pesquisa Nível 2 do CNPq. E-mail: cidobyl@pq.cnpq.br Orcid: https:// orcid.org/0000-0002-2073-5042
}

Data de submissão: dez. 2020 - Data de aceite: mar. 2021 http://dx.doi.org/10.5335/rdes.v17i01.11291 
tura de mudança e intersecção é o objeto deste artigo, que enseja uma leitura de unidades de Fragmentos de um discurso amoroso, de 1977, adotando como recorte as relações que ali aparecem entre amar, escrita e língua, donde puxaremos fios de aspectos mais amplos do livro e da obra de Barthes.

Apesar de não ser estritamente ficção nem poesia, Fragmentos transita por algumas fronteiras que também a literatura está sempre a renegociar, como a trama de narração, elocução e autoria; os encaminhamentos e descaminhos que vinculam projeto autoral e aspectos composicionais, e as instáveis relações entre literatura e os parâmetros de práticas discursivas que lhe são intermitentemente outras (filosofia, crítica); por isso, utilizamos um ferramental de estudos literários. Partimos da definição de Lopes (1994, p. 322), que considera a literatura uma "inquietação das formas, um movimento em que a deformação da sintaxe aparece como condição do sentido", para ler os Fragmentos em rede com seus arredores escriturais (diários, cursos, artigos), atentando a recorrências de proposta e fundamentos, bem como ao ethos do locutor textual e ao que este implica para composição e leitura. Portanto, este artigo integra o crescente número de pesquisas que tratam Barthes como um escritor, isto é, alguém que não se utiliza da linguagem, mas nela se aventura, numa relação difícil.
Fragmentos integra o ciclo de escritos barthesianos que acabou sendo o derradeiro, no qual o caráter ensaístico da escrita parece prevalecer sobre 0 aspecto teórico dos escritos. No entanto, como veremos, a escrita ensaística, longe de abandonar as reivindicações teóricas (no tocante, por exemplo, a acepções de escrita, sujeito e outras bandeiras pelas quais Barthes bateu-se publicamente nas décadas precedentes), pressupõe-nas e as integra. Nesse sentido, conforme o livro coloca em questão, ou em jogo, não apenas um objeto (o discurso amoroso), mas também o seu próprio fazer enquanto escrita que se quer amorosa, a própria prática de escrever é ali recolocada em outros termos, no interminável de uma ferida.

\section{Na ponta da língua}

Ao abrir Fragmentos de um discurso amoroso, encontramos dois pequenos textos e, em seguida, uma página quase vazia que proclama em letras garrafais: "É pois um amante que fala e que diz" (BARTHES, 2003, p. 1). Esta espécie de fórmula mágica instaura o espaço de fala reivindicado pelo livro por meio da caracterização do locutor. É ele o pivô a partir do qual serão convocados discursos diversos - textos psicanalíticos, filosóficos, poemas, o inclassificável Tao, passagens de romances (em especial $O s$ sofrimentos do jovem Werther, de Goethe) - para serem difratados pela ótica 
do apaixonado, que deles tece seu dizer sem grande preocupação com o lastro nem com os alicerces que afiançam os textos mordiscados nessa composição.

Fragmentos propõe-se a dramatizar um discurso. Em cena, uma única boca: a tipologia discursiva seria o solilóquio, "alguém que fala em si mesmo, amorosamente, em face do outro (o objeto amado), que não fala" (BARTHES, 2003, p. XVII). Mesmo sem falar, o outro está presente no discurso do apaixonado, que a ele se dirige, inconsolável, nas Figuras que leremos.

Figura é o nome dado às unidades do livro, que picota o Discurso Amoroso para apresentar um conjunto (não exaustivo) do que chama Figuras, oitenta cenas do "amante em ação" (BARTHES, 2003, p. XVIII), dispostas em ordem alfabética. Antes das tais Figuras, um pequeno texto intitulado "Como é feito este livro" explica que tal disposição intende preservar o caráter combinatório e fragmentário da proposta. Cada Figura é formada por um título, um caput ou argumento e um desenvolvimento em fragmentos numerados.

Vejamos:

A carta de amor $\S^{1}$ CARTA. A figura visa a dialética particular da carta de amor, ao mesmo tempo vazia (codificada) e expressiva (carregada da vontade de significar o desejo $^{2}$ (BARTHES, 2003, p. 45).

Na carta de amor pesa imenso o endereçamento. $\mathrm{O}$ primeiro fragmento da Figura esquematiza cartas do jovem Werther a sua amada Carlota, que afinal poderiam ser resumidas por "penso em você". Há um contraste entre essas cartas e as endereçadas ao amigo Wilhem (o romance de Goethe é epistolar e Wilhem é o principal correspondente do protagonista), repletas de eventos, relatos e reflexões acaloradas, ainda que orbitando a paixão por Carlota; afinal, o que é escrito entre os amantes aparece como menos relevante do que a proximidade em que são colocados pela troca de missivas: "nada tenho a dizer a você, senão que este nada é a você que o digo" (BARTHES, 2003, p. 46, grifo do autor).

Outro ponto levantado na Figura é que, assim como o solilóquio de Fragmentos, a carta de amor é uma fala propiciada pela ausência de quem se ama e dirigida a essa pessoa. Diferentemente do livro, no entanto, a carta teria uma missão bem definida: fazer-se presente, fazer sentir o desejo de copresença.

No segundo fragmento é aventada e rejeitada a ideia de um uso tático da carta de amor: sem querer conquistar ou estimular o afeto do outro, a carta de amor seria, para o amante, desprovida de objetivos - seria uma atividade que se basta, como um carinho ou uma declaração, título de outra Figura, onde se lê:

A linguagem é uma pele: fricciono minha linguagem contra o outro. Como se eu tivesse palavras à guisa de dedos, ou dedos na ponta de minhas palavras. Minha linguagem treme de desejo. A comoção vem de um duplo 
contato: de um lado, toda uma atividade de discurso vem realçar discretamente, indiretamente, um significado único, que é "eu te desejo", e libera-o, alimenta-o, ramifica-o, fá-lo explodir [...]. Falar amorosamente, é gastar infinitamente, sem crise; é praticar uma relação sem orgasmo. ${ }^{4}$ (BARTHES, 2003, p. 99-100).

Dirigir-se ao outro ternamente, num platô infindável, poderia ser o próprio paraíso, se essa repetição não agravasse o vulto da falta donde brota o desejar e que propele a linguagem como demanda. Tal linha de raciocínio e vocabulário acenam à Psicanálise, que integra de viés o terceiro fragmento da Figura 'Carta de amor': com um trecho de correspondência onde o jovem Freud admoesta sua noiva pelo silêncio, somos lembrados de que a carta endereçada ao amado solicita, sim, algo: uma resposta.

Questões como o endereçamento e as relevâncias díspares da mensagem e do gesto de dirigir-se a alguém integram também outra Figura:

A dedicatória. § Dedicatória. Episódio de linguagem que acompanha todo presente amoroso, real ou projetado, e, mais geralmente, todo gesto, efetivo ou interior, pelo qual o sujeito dedica alguma coisa ao ser amado. ${ }^{5}$ (BARTHES, 2003, p. 103).

No primeiro fragmento alude-se à busca do presente perfeito a ser oferecido a quem se ama e toda a carga desejante investida nessa passagem. $\mathrm{O}$ segundo fragmento da Figura interessa-se pelo perigo de fracasso dos presentes, que redunda num fracasso do presentear enquanto aproximação. Já o quarto fragmento de 'Dedicatória' traz diretamente a escrita:

"A esse deus, ó Fedro, dedico este discurso..." Não podemos dar linguagem (como fazê-la passar de uma mão para outra?), mas podemos dedicá-la - pois que o outro é um pequeno deus. O objeto dado é reabsorvido no dizer suntuoso, solene, da consagração, no gesto poético da dedicatória [...]; é o princípio mesmo do Hino. Não podendo dar nada, dedico a própria dedicatória, no que se absorve tudo o que tenho a dizer [...].

O canto é o suplemento precioso de uma mensagem vazia, inteiramente contida em seu endereçamento, pois o que dou cantando é ao mesmo tempo meu corpo (através da minha voz) e o mutismo com o qual você o golpeia. (O amor é mudo, diz Novalis; apenas a poesia o faz falar.) $O$ canto nada quer dizer: é por isso que você entenderá por fim que o estou dando a você; tão inútil quanto o fiapo de lã, a pedrinha, oferecidos à mãe pela criança. ${ }^{6}$ (BARTHES, 2003, p. 106-107, grifos do autor).

$\mathrm{O}$ ato de ofertar um canto diz a um tempo do endereçamento que alinhava aquela fala e da condição dilacerante que desfaz naquele que a profere a capacidade de dizer algo além dessa oferta. $\mathrm{O}$ endereçamento é precioso e suplemento, termo derridiano para um modo de imbricação no qual um elemento ou força percebidos como externos a um processo mostram-se determinantes para sua constituição, seja enquanto adição que leva a uma plenitude ou enquanto marca de um vazio constitutivo (DERRIDA, 1967).

No quinto fragmento o perigo do fracasso retorna, conforme o presente-texto 
se mostra inevitavelmente pontiagudo, hostil:

Entretanto, salvo o caso do Hino, que confunde o envio e o próprio texto, o que se segue à dedicatória (a saber, a própria obra) tem pouca relação com essa dedicatória. $\mathrm{O}$ objeto que dou não é mais tautológico [...], é interpretável; tem um sentido (sentidos) que ultrapassa de muito seu endereçamento; por mais que eu escreva seu nome em minha obra, é para "eles" que ela foi escrita (os outros, os leitores). É, pois, por uma fatalidade da própria escrita que não se pode dizer de um texto que ele é amoroso, mas apenas, a rigor, que foi feito "amorosamente", como um bolo ou uma pantufa bordada.

E mesmo: menos ainda que uma pantufa! Pois a pantufa foi feita para seu pé [...]. Mas a escrita, esta não dispõe desta complacência. ${ }^{7}$ (BARTHES, 2003, p. 107-108, grifo do autor).

As imagens do bolo e da pantufa amenizam com humor a gravidade da enrascada do apaixonado que sonha agradar com algo espinhoso como um texto. Leyla Perrone-Moisés nota que tais comparações cômicas requerem que o locutor textual de Fragmentos tome alguma distância de seu estar-apaixonado. Fica então evidente que o "amante que fala e que diz" é também, às vezes, analista irônico; contudo,

[...] resta a qualidade do discurso produzido, que não é nem pesado de saber nem esmagador de sarcasmo, mas simpatizante dos logros inocentes em que se debate o apaixonado (PERRONE-MOISÉS, 2012a, p. 94, grifo do autor).

Esse locutor, que é analista compadecido e também apaixonado, que está imerso na questão e também dela ligeiramente recuado, convida o leitor a essa mesma flutuação. Perrone-Moisés (2012b, p. 96) aponta que

[...] o livro de Barthes não é um tratado sobre o amor, é um livro que dá a palavra a um sujeito enamorado - fictício, composto da experiência de vários, mas corporificado pelo artifício da primeira pessoa.

Pino (2011, p. 217-218) explica que Barthes, ao entrançar diferentes discursos apaixonados, acaba produzindo o discursar amoroso como um "acúmulo de repetições de vários sujeitos": ele mesmo, seus amigos, poetas, romancistas. Essas repetições permitiriam ao enunciador do discurso amoroso e ao leitor a visão de que ali há apenas uma demanda sem resposta; essa visão "não é paralisante: pelo contrário, é o começo da escritura, de uma crítica em relação a uma postura anterior", e também de uma cumplicidade entre os apaixonados - eles, sim, unidos pelo livro.

Voltando ao problema enfrentado pelo dedicador apaixonado de um texto, prossigamos a leitura: "mas a escrita, esta não dispõe desta complacência. A escrita é seca, obtusa; é uma espécie de rolo compressor; segue em frente, indiferente, indelicada; preferiria matar 'pai, mãe, amante' a se desviar de sua fatalidade (de resto, enigmática)" (BARTHES, 2003, p. 108). A fatalidade da escrita, tão esquiva a deixar-se fazer amorosamente, a permitir que alguém 
nela entre com um desígnio e saia, intacto, com o produto esperado, está ligada à sua qualidade de processo, que faz vacilar contexto, sujeito e a própria noção de intencionalidade. Fruto desse vórtice, o texto fatalmente excede o gesto de dedicar e opõe-lhe recusa obtusa, sendo assim "uma obra que nos escapa a ambos", sentencia o sexto fragmento da Figura.

Como o texto opera todos esses abalos? Desestabilizando a acepção da escrita como criação realizada por um sujeito monádico, que seria o ponto de referência para estabelecimento de contexto e articulação de intencionalidade, os quais funcionariam como delimitadores para a significação irrefreável do texto. Esses limites fariam referir à autoridade da figura do Autor os significados admissíveis num texto portando sua assinatura. Essa concepção proprietária da escrita sofreu uma leva de ataques críticos nas décadas de $1960-70^{9}$, e um dos aríetes arremetidos contra ela foi o programático artigo "Da obra ao texto", de 1971, no qual Barthes explica que

[...] o Texto pode ser lido sem a garantia de seu pai; a restituição do intertexto vem abolir paradoxalmente a herança. Não é que o Autor não possa "voltar" ao Texto, no seu texto; mas será, então, por assim dizer, a título de convidado (BARTHES, 2012a, p. 72).

Entretanto, essas contestações do lugar do Autor na leitura e na crítica literárias interessam menos, aqui, do que os correlatos abalos que ameaçam o sujeito em situação de prática da escrita, a qual incomoda em 'Dedicatória'. Esses abalos aparecem na provocação "Escrever, verbo intransitivo?", de 1966, onde Barthes (2012b) aproveita algumas categorias linguísticas para pensar esses abalos com foco no que lhe parece ser a situação do escritor moderno para com a escritura. As proposições são formuladas a partir da teoria enunciativa do linguista Émile Benveniste, que Barthes, sem aplicar propriamente, maneja por homologia.

Conforme sublinham Flores e Endruweit (2012), as noções benvenistianas estão articuladas em rede e formam um construto conceitual dinâmico. Para Bellocchio (2017), a leitura de Benveniste auxiliou Barthes a formular ideias e conexões que ele já vinha desenvolvendo por conta própria, algumas das quais são relevantes para pensar como o texto-presente extrapola a dedicatória em Fragmentos. Em vista disso, apresentaremos de modo instrumental, a partir de textos integrantes dos dois volumes de Problemas de Linguística Geral, três dos principais pontos em que as propostas de Benveniste são afins às pesquisas de Barthes e delas participam: 1) enunciação, 2) discurso e 3) relações entre subjetividade e linguagem.

A enunciação é o ato de exercício de linguagem pelo locutor, que se apropria de sua língua numa situação particular 
e intersubjetiva (para Benveniste, há sempre um alocutário, efetivo ou postulado) e produz um discurso. Em "O aparelho formal da enunciação", Benveniste (2005, p. 80) define a enunciação como

[...] colocar em funcionamento a língua por um ato individual de utilização. [...] é o próprio ato de produzir um enunciado, e não o texto do enunciado, que é nosso objeto ${ }^{10}$.

Cada enunciação é única, ainda que os interlocutores e as palavras trocadas sejam "os mesmos", na não-identidade do bom dia que se deseja a uma "mesma" pessoa por anos a fio.

O discurso é instância singular de atualização da língua por um locutor (BENVENISTE, 2014), em que este se instaura enquanto tal. $\mathrm{O}$ discurso tem uma realidade transindividual, pois consiste na apropriação de um sistema (a língua) partilhado com um coletivo e realiza-se como solicitação ou postulação de um outro, a quem o locutor se dirige efetiva ou virtualmente (BENVENISTE, 2014). Compreendemos que o discurso englobe $o$ ato de enunciação, o enunciado e as relações desses elementos cujas fronteiras são apenas analíticas.

Por fim, para Benveniste, é na linguagem que estão as condições e o lugar de conceitualização, produção e realização da subjetividade, que só existe empiricamente enquanto ponto axial do discurso. Assim, "Eu" é quem, em torno de "eu" - significante cujo referente é intradiscursivo - estabelece os eixos de referência espacial e temporal num aqui-agora fundados a cada enunciação, conforme explica Benveniste (2014, p. 252-254, grifos do autor) em "A natureza dos pronomes":

Qual é, então, a "realidade" a que se refere eu ou $t u$ ? Unicamente uma "realidade de discurso", que é algo bastante singular. $E u$ somente pode ser definido em termos de "locução", não em termos de objetos, como acontece com um signo nominal. [...] eu é o "indivíduo que enuncia a presente instância de discurso contendo a instância linguística $e u$ ". [...]. Esse signo está, então, ligado ao exercício da linguagem, e declara o locutor enquanto tal. É essa propriedade que funda o discurso individual, onde cada locutor assume por si próprio toda a linguagem (..... ${ }^{11}$

Uma vez que o sujeito só se constitui na linguagem, a enunciação é ao mesmo tempo ato de ação linguística e processo de subjetivação, de formação de uma subjetividade vigente no e pelo discursar. A partir de Benveniste, pondera Barthes em "Escrever, verbo intransitivo?":

[...] o eu do discurso já não pode ser o lugar onde se restitui inocentemente uma pessoa previamente guardada. O recurso absoluto à instância do discurso para determinar a pessoa [...], por mais imperfeito que possa ser ainda o seu exercício, aparece então como uma arma contra a má-fé geral de um discurso que não faz ou não faria da forma literária mais que a expressão de uma interioridade constituída atrás e fora da linguagem. (BARTHES, 2012b, p. 20, grifo do autor).

Reencontramos, aqui, algo próximo da "fatalidade própria à escrita" que envenenava o texto-presente que, pa- 
rágrafos acima, o apaixonado dedicava com amor. Naquele texto, quem escreve produz um enunciado às custas de produzir-se enquanto enunciador (isto é, de indeterminar-se enquanto origem prévia), inédito e fugaz - "o sujeito constitui-se como imediatamente contemporâneo da escritura, efetuando-se e afetando-se por ela" (BARTHES, 2012b, p. 23).

Todavia, aqui cabe retomar o alerta que precedeu esta esquemática apresentação de conceitos de Benveniste que subsidiam a reflexão barthesiana: assinalamos que Barthes propunha trabalhar, em "Escrever, verbo intransitivo?", por homologia. Isso porque os trabalhos de Benveniste nos Problemas de linguística geral dizem respeito à fala, não à escrita ${ }^{12}$. Assim, qualquer transposição de suas concepções e categorias para pensar a escrita, e em especial a literatura, é necessariamente uma adaptação e requer, portanto, cuidados e atividade criadora.

A importância dessas noções de Benveniste em Fragmentos de um discurso amoroso evidencia-se já pela presença de uma delas no próprio título do livro. $\mathrm{Na}$ mesma linha, vale notar que Fragmentos foi escrito a partir de dois cursos ministrados por Barthes na École Pratique des Hautes Études, e que o objeto-título do primeiro curso era justamente "Problemas da enunciação: o discurso amoroso" (BARTHES, 2007, p. 51). Essa relação intertextual renderia um estudo à parte, para o qual talvez contribua o presente artigo ao adotar por recorte as figuras nas quais aparecem (são figuradas, discutidas) situações de produção linguística escrita do apaixonado e onde se entrelaçam, por conseguinte, a simulação do discursar amoroso - forma escritural em cuja formulação estão presentes noções analíticas, como as de enunciação, discurso e texto - e reflexões, ou enunciados, que interrogam as possibilidades da escrita para ser, ela mesma, uma produção linguística amorosa.

Dentre as inumeráveis decorrências dessa dobra, marcamos aqui a diferença de valor: os abalos festejados e afirmados na teorização barthesiana do Texto consistem, para o dedicador apaixonado, em motivo de lamento. Voltando finalmente às deficiências do texto como presente na figura 'Dedicatória', temos que o incontrolável da escrita e da proliferação significante do texto, que era bem-vindo no relativo anonimato e distância entre autores e leitores, parece, na intersubjetividade específica da dedicatória amorosa de um texto, nocivo:

(Verificamos muitas vezes que um sujeito que escreve não tem de modo algum a escrita de sua imagem privada: quem me ama "por mim mesmo" não me ama por minha escrita (com o que sofro). Sem dúvida, porque amar ao mesmo tempo dois significantes num corpo é demais! Isso não é nada comum. E se por exceção isso acontece, trata-se da Coincidência, do Soberano Bem.). ${ }^{13}$ (BARTHES, 2003, p. 109). 
A relação de excedência ou impermeabilidade entre a escrita e aquele que a assina é, para autores da estatura de Maurice Blanchot, algo que embaraça a distinção entre posicionamento e fatalidade. Contudo, nos escritos de Barthes, a recorrência desse intervalo aparece antes como inquietação a que ele retorna e na qual trabalha.

No parêntese citado, desliza-se do nós em "Verificamos" (conjunto de escritores para quem a imagem privada difere da imagem pública da escrita) ao $e u$ que isso faz sofrer. Esse eu, esse amante que fala nos Fragmentos, é um dos principais pontos na fortuna crítica do livro.

Vimos há pouco, com Perrone-Moisés (2012b) e Pino (2011), que esse enunciador abriga um caleidoscópio de falantes fictícios e históricos. Dentre eles está Roland Barthes, nome próprio que abarca também um plural. Em 1986, pondera Roger (1986, p. 191, grifos do autor, tradução nossa):

[...] o eu "intratável" é mesmo, aqui, o lugar de um compromisso: escrevendo, ele sacrificará, sacrificou "um pouco" de seu Imaginário. $\mathrm{O}$ eu de Fragmentos... é um pouco menos apaixonado do que o eu do solilóquio. Entre eles, há o texto, que "não descreve" o sujeito amoroso, e sim compõe com o pathos.

Roger levanta um ponto crucial em Barthes: a escrita enquanto distanciamento, tanto da experiência que pretensamente descreveria - mas, como veremos com Derrida (2004), mais faz abrir em abismo - quanto dos vários eus, os enunciadores que escrever integra, conjuga e fissura: o apaixonado que profere o solilóquio, o autor que decupa o enamoramento em figuras reunidas num livro, o escritor que trabalha suas crises pessoais na escrita. Quanto a este: circulava, já na época da publicação de Fragmentos de um discurso amoroso, a anedota biográfica de uma paixão de Barthes concomitante aos seminários que antecederam e prepararam a escrita do livro. Trinta anos depois, a edição de materiais desses seminários (BARTHES, 2007) trouxe informações sobre o processo de redação de Barthes, do qual fazia parte um caderno assim descrito pelo organizador do volume, Claude Coste (2007, p. 41-42, tradução nossa):

[...] uma espécie de diário íntimo ou diário apaixonado que ilumina o modo como Roland Barthes encara a relação entre a vida, a pesquisa e o livro. [...]

A primeira parte, "Cronologia", é composta de 23 páginas manuscritas, redigidas entre 20 de setembro de 1974 e $1^{\circ}$ de fevereiro de 1976: o texto começa, pois, alguns meses antes do início do primeiro seminário (janeiro de 1975) e termina no início do segundo seminário. Cada página dupla do caderno está dividida em quatro colunas: a primeira lista datas sucessivas; a segunda, intitulada "Narrativa", enumera os eventos correspondentes. As pessoas (o objeto amoroso, amigos, familiares do autor...) evocadas nessas anotações de poucas linhas são, no mais das vezes, designadas pela inicial de seus nomes (ou de nome e sobrenome), e raramente pelo nome por extenso. Já na "Narrativa", portanto, ao evitar os nomes próprios, o diarista manifesta a mesma discrição e, sobretudo, a mesma distância referencial que caracteriza o escritor dos Fragmentos de um discurso 
amoroso. Prosseguindo, na terceira e na quarta colunas, esse duplo trabalho de recuo e classificação, Roland Barthes propõe sucessivamente para cada acontecimento uma "Figura" e uma "Plaqueta" - como fará em seu seminário e posteriormente no livro. [...] Isso sinaliza claramente que Roland Barthes, apaixonado, professor e escritor, vivia, por assim dizer, simultaneamente um triplo projeto, ao mesmo tempo existencial, pedagógico e literário [...]. ${ }^{14}$

Esse trânsito ou intersecção entre experiência e escrita que, nem bloqueado nem escancarado, é antes trabalhoso em Barthes, aparece num diário publicado postumamente sob o título Diário de luto: "Crença e, parece, verificação de que a escrita transforma em mim as "estases" do afeto, dialetiza as crises. [...] $\S$ Crise Olivier $\rightarrow$ Sobre Racine. § Crise $\mathrm{RH} \rightarrow$ Discurso amoroso" (BARTHES, 2011, p. 102, grifos do autor).

Retomando o ceticismo de Barthes quanto à acepção de uma escrita, autobiográfica ou não, em que a língua fosse instrumento de expressão dum sujeito a ela prévio e externo, e sabendo que ele cogitava incorporar o Diário de luto a seu projeto de romance (BARTHES, 2002; PINO, 2015), trazemos esse trecho menos para ratificar a concepção de um fluxo direto entre vida e escrita do que como um espaço performativo integrante da imagem de autor que Barthes lavrava incessantemente e que, em especial na década de 1970, é marcada por uma cuidadosa permeabilidade entre público e privado (OLIVEIRA, 2015).
Para Coste (2016), essa é uma diferença relevante entre Barthes e Blanchot pensadores e escritores: enquanto Blanchot operaria com a obra fundada na morte do mundo e do sujeito, e deles irrecuperavelmente apartada, Barthes manteria a relação entre realidade e obra, fazendo desta uma modalidade daquela. Entretanto, apesar do que insiste Blanchot em suas incursões teóricas, a questão pode ser menos nítida quando se trata de suas narrativas.

Em Demeure - Maurice Blanchot, Jacques Derrida é movido por uma narrativa em que Blanchot escreve ter estado a ponto de ser fuzilado. Ele parte desse escrito que poderia ter sido um relato para refletir sobre o estatuto do testemunho e as relações que este demanda entre ficção e autobiografia, tomando-as como dimensões estruturalmente integrantes uma da outra e que perturbam, nessa interdependência, uma série de antinomias - veracidade e mentira, fidelidade e perjúrio etc. (DERRIDA, 2004). Destaca-se como ponto de contato entre as considerações de Derrida e Fragmentos a iterabilidade, que está no princípio do testemunho como a copresença de repetir e diferir: entre o biográfico do escritor, o texto e seu ressoar junto aos leitores, há espaço para múltiplos deslizares entre identidade e deslocamento.

Esses e outros descolamentos fazem do texto um presente mais do que impróprio - inviável, diz o sexto fragmento de 
'Dedicatória': "Não posso pois dar a você o que acreditei escrever para você, é a isso que devo me render: a dedicatória amorosa é impossível"15 (BARTHES, 2003, p. 109). Todavia, como bem lembram Blanchot (1962) e Barthes (2003), o impossível não necessariamente interdita a escrita, sendo por vezes sua condição inicial; assim, o apaixonado procura o que pode haver de interessante na diferença operada pelo texto no amado, que ali talvez não se reconheça:

A operação na qual o outro é envolvido não é um sobrescrito. É, mais profundamente, uma inscrição: o outro está inscrito, inscreveu-se no texto, deixou seu rastro, múltiplo. Se, deste livro, você fosse apenas o dedicatário, você não sairia de sua dura condição de objeto (amado) - de deus; mas sua presença no texto, pelo próprio fato de você ser aí irreconhecível, não é a de uma figura analógica, de um fetiche, é a de uma força que não está, consequentemente, em repouso absoluto. ${ }^{16}$ (BARTHES, 2003, p. 109, grifo do autor).

O dedicador apaixonado toma aqui o partido da escrita, em prol da qual argumenta para o outro: veja, isso que te magoa, é na verdade ternura. Estar entranhado nesse escrito, integrá-lo na qualidade de força ao invés de ser nele um mero elemento, é apresentado como atrativo, pois, fora de um esquema de representação, ser rastro conferiria ao outro uma mobilidade vital.

"Rastro" é a tradução brasileira consagrada para o francês trace, termo derridiano que coloca em questão a necessidade ou a existência de um ponto inicial, de uma origem. $\mathrm{O}$ rastro se subtrai à oposição ausência/presença: enquanto presença de uma ausência irredutível, ele é a recusa de um começo, de um elo primeiro que ligasse a cadeia de significação a algo fora de seu jogo interno de diferenciação. Nos pensamentos de Derrida (1967; 2004), o questionamento é dirigido ao que ele denomina metafísica da presença; nos limites deste estudo, o rastro implica sustar a referência. Desse modo, participar da dinâmica da escrita nos termos da escrita, infiltrar-se nessa atividade arredia e irrenunciável, aparece como um presente sem preço - no exato momento em que o par apaixonado se sente escapar entre os dedos, é para entrar na medula. Impossibilitado de dedicar um texto, o apaixonado dirige-se diretamente ao outro ("Se, deste livro, você fosse apenas o dedicatário...") para oferecer essa impossibilidade como gesto de amor; assim, "saber" ou estar ciente de que a oferta do texto é inútil e impraticável não cala o seu apelo.

A danosa travessia do amor no texto é o caroço da Figura 'Escrever': "Inexprimível amor § EsCREvER. Engodos, debates e impasses provocados pelo desejo de 'exprimir' o sentimento amoroso numa 'criação' (particularmente de escrita)"17 (BARTHES, 2003, p. 157).

O título e as aspas que corroem "exprimir" e "criação" marcam a suspeita que dá o tom da Figura. O segundo fragmento recorre ao indireto e pergunta se 
acaso a escrita do amor não poderia ser uma questão de ajuste: de um trabalho que obtivesse uma enunciação adequada. O ajustar do dizer é um dos pontos esmiuçados com mais afinco no estudo de Fragmentos em que Marty (2006) destrincha diversos procedimentos pelos quais o livro esquiva o que o pesquisador denomina, numa apropriação da terminologia lacaniana, abordagem ao modo simbólico. Segundo Marty (2006), o modelo simbólico era característico da prática reflexiva da época de publicação de Fragmentos e consistiria, resumidamente, em considerar que a teoria, enquanto tipo particular de práxis, era capaz de agir sobre os objetos que estudava (e dos quais era, portanto, distinguível) ao incidir sobre o jogo de forças e de percepções no qual seus objetos se davam. Para Marty (2006), Barthes teria investido numa dinâmica mais próxima do Imaginário, caracterizada pela utopia de uma indiferenciação que vigoraria tanto entre apaixonado e amado quanto entre o discurso e a experiência amorosos: irredutíveis um ao outro, seriam também inextricáveis: em lugar de um agir sobre o outro, estariam em conjunção, enovelados.

Uma estrutura discursiva desenhada no Imaginário traz diversos aspectos de interesse, dentre os quais destacamos a pouca importância que ali têm a autoridade ou a legitimação (diferentemente do Simbólico, estruturado pelo advento da
Lei); em Fragmentos, isso aparece como abandono de uma estratégia discursiva modelar, a qual desenha a obtenção de assentimento do leitor, em favor de algo menos hierarquizado: sem estabelecer verdades sobre o amor, o apaixonado dos Fragmentos tão-somente diz que (também) ama ${ }^{18}$.

O segundo fragmento de 'Escrever' enseja pequenos poemas e conclui: "Sou ao mesmo tempo grande demais e fraco demais para a escrita: estou ao lado dela, que é sempre rigorosa, violenta, indiferente ao eu infantil que a solicita. $\mathrm{O}$ amor tem decerto um pacto com minha linguagem (que o mantém), mas não pode alojar-se em minha escrita"19 (BARTHES, 2003, p. 159, grifos do autor).

Escrever o amor é outra grande busca barthesiana da época. O projeto final de Barthes era um romance, esforço que originou seu último curso no Collège de France (A preparação do romance). Num plano desse romance, há a ideia de retirar-se dos afazeres mundanos para "empreender uma grande obra onde seria dito... o Amor" (PINO, 2015b, p. 113). Nesse caso, dizer o amor não é exprimir ou representar uma vivência, e sim tentar engendrar na escrita o amor como efeito de leitura (PINO, 2011). É esse o salto que falta neste segundo fragmento de 'Escrever': voltado ainda à expressão, aquele que pretende escrever seu amor desespera-se perante a opacidade da linguagem. 
A escrita do Imaginário é citada no terceiro fragmento de 'Escrever' como o menor dos males possíveis em termos de escrita amorosa, e que requereria um compromisso entre o Imaginário amoroso e o da escrita, cada qual com exigências próprias, frequentemente incompatíveis, que assolam quem se vê mergulhado n'ambos ao mesmo tempo.

Uma dessas incompatibilidades é que escrever exigiria do apaixonado distância em relação ao que gostaria de exprimir, distância necessária tanto para poder manejar (em termos composicionais) sentimentos, o outro etc. quanto para aceder à desestabilização de si que, como vimos ao ler 'Dedicatória', integra a prática da escrita. Diz o terceiro fragmento de 'Escrever':

Quem seria este eu que se escreveria? À medida que entrasse na escrita, a escrita o esvaziaria, o tornaria vão; produzir-se-ia uma degradação progressiva, na qual a imagem do outro seria, também ela, pouco a pouco envolvida (escrever sobre alguma coisa é corromper esta coisa), abominação cuja conclusão não poderia deixar de ser: para quê? O que bloqueia a escrita amorosa, é a ilusão de expressividade: escritor, ou considerando-me tal, continuo a me enganar sobre os efeitos da linguagem [...]. Alguém deveria me ensinar que não se pode escrever sem fazer o luto da própria "sinceridade" (sempre o mito de Orfeu: não se virar) ${ }^{20}$ (BARTHES, 2003, p. 159-160, grifos do autor).

Luto da sinceridade e ilusão da expressividade: eis a grande questão da crise da referência, perene para Barthes e muitos de seus contemporâneos. Ela está na base da crítica barthesiana de mecanismos pelos quais procura-se negar ou burlar os intervalos entre linguagem e experiência, apresentando a primeira como decalque da segunda. Por exemplo, em seu primeiro livro, O grau zero da escrita, ele comenta o uso do tempo verbal francês passé simple que, em desuso na oralidade e restrito à escrita, opera um efeito de organização temporal dos eventos narrados (BARTHES, 2004b) em que esse uso convencionado da língua sinaliza o próprio fazer artístico, inclusive ou talvez especialmente nos romances chamados realistas.

Sem desprezar as alterações e nuances ocorridas ao longo de quase três décadas de reflexão, é possível dizer que Barthes costuma apresentar em chave eufórica as intermitências entre linguagem e experiência: como potencialidade e libertação, elas subjazem ao plural constitutivo do texto festejado em ensaios célebres como o já citado "Da obra ao texto" (BARTHES, 2012a), à autarquia pela qual a estruturação interna à literatura pode ofuscar algum aspecto referencial, e redundam em amplitude de movimento para a aproximação crítica, uma vez que as leituras, no esteio das obras literárias, explodem em possibilidades sem fim.

O fragmento final de 'Escrever' assume e postula uma falência: "saber que não escrevemos para o outro, saber que essas coisas que vou escrever jamais me farão amado de quem amo, saber que a escrita não compensa nada, não sublima 
nada, que ela está precisamente ali onde você não está - é o começo da escrita"21 (BARTHES, 2003, p. 161, grifo do autor).

Próximo das proposições de Blanchot (1997), Barthes finca o marco inicial da escrita numa série de desprendimentos, num umbral onde quem se dispõe a escrever deve abandonar qualquer projeto ou resultado. No entanto, conforme Pino (2011, 2015) e Marty (2006), a renúncia a um certo resultado pode significar a abertura a múltiplas decorrências, e dentre esses vários e imprevisíveis efeitos está a oferta do texto enquanto percurso ao leitor. Assim, ao abrir mão de um determinado amor (da pessoa amada a quem se dirige o locutor apaixonado), o texto fica disponível para acolher incontáveis outros amores - os leitores que, nalguma medida, apaixonam-se um pouco com e por esse apaixonado, ou encontram conforto numa outra união: "compartilhar o fracasso do amor, e nesse compartilhamento, vivemos algum tipo de união amorosa. Não se trata de um amor alegre, não se trata da felicidade de possuir um objeto, mas da constatação que não sou o único a não possuir esse objeto" (PINO, 2011, p. 221).

\section{A língua de soslaio}

Com efeito, os Fragmentos parecem lamentar uma incompatibilidade entre o amor alegre e uma escrita dele decorrente. Contudo, se até aqui a escrita tem aparecido como a parte intransigente dessa relação, ela não é a única a cavar esse fosso.

Como nota Pino (2011), várias Figuras de Fragmentos sonham com união, indiferenciação, fusão e comunhão entre os seres. Uma delas é 'Plenitude':

Plenitudes: não são ditas - de modo que, falsamente, a relação amorosa parece reduzir-se a um longo lamento. [...] o eu só discorre ferido; quando estou pleno ou me recordo de assim ter estado, a linguagem me parece pusilânime: sou transportado para fora da linguagem, quer dizer, para fora do medíocre, para fora do geral [.... . ${ }^{22}$ (BARTHES, 2003, p. 276-277, grifo do autor).

Uma porção importante do estar-apaixonado parece, então, furtar-se à linguagem, que opera na, por e enquanto falta, que não tem lugar na plenitude - pela qual suspira e labora, ansiando pelo repouso da cessação ou, ao menos, o fôlego da suspensão.

O lado analista do apaixonado lembra que

[...] na realidade, pouco me importam minhas chances de ser realmente pleno (admito que elas sejam nulas). Brilha apenas, indestrutível, a vontade de plenitude. Por essa vontade, derivo, formo em mim a utopia de um sujeito subtraído ao recalque: já sou esse sujeito. ${ }^{23}$ (BARTHES, 2003, p. 277, grifo do autor).

A utopia, ou o vislumbre de estados paradisíacos cuja exequibilidade importa menos do que a formulação, encontra novamente a divisa apaixonada "sei disso, ainda assim...”. 
Pela estruturação fragmentária e permutável, estrelada por um "eu" também fraturado, Fragmentos se quer avesso a preocupações de consistência; no entanto, podemos ainda encontrar ali insistências. Repetições costumam ser repudiadas pelas diretrizes da boa composição, segundo as quais um discurso, por ser veículo de um raciocínio, deve avançar - de preferência rumo a uma conclusão; em literatura, contudo, a repetição pode ser revalorizada como recorrência e sinalizar a importância de uma estrutura, recurso, imagem etc. naquele lance discursivo. Assim, se as hesitações e revisões constantes em Fragmentos contribuem para despojar suas páginas de qualquer pretensão de circunscrever, descrever ou solucionar o estado amoroso - como exploramos melhor alhures (OLIVEIRA; BYLAARDT, 2019) -, a insistência com que certos pontos afloram ao longo das páginas pode entregar tais questões ao leitor.

Nessa linha, o caráter prescindível da linguagem parece ser reafirmado por sua ausência em algumas figuras que visitam, na qualidade de aspiração, a união total com o ser amado, como 'Abraço' e 'União'. Desse modo, os Fragmentos parecem sugerir algo como uma repulsa recíproca entre amor feliz e expressão verbal, e que tampouco em ações inexpressivas da língua (a escrita inóspita e deformadora, como visto há pouco) o amor poderia habitar.
Esse problema sem resposta talvez tenha brechas. Barthes costuma preferir tentativas a soluções definitivas; a harmonia provisória encontrada nos Fragmentos entre linguagem e amor feliz é a seguinte: em face dos atritos entre as dinâmicas da união amorosa $\mathrm{e}$ as da expressão e da criação verbais, o apaixonado pode buscar outros fazeres na língua, em que algumas de suas determinações sejam afrouxadas. Um deles aparece na Figura 'Tal':

Acedo então (fugitivamente) a uma linguagem sem adjetivos. Amo o outro não segundo suas qualidades (contabilizáveis), mas segundo sua existência; por um movimento que bem poderíamos dizer místico, amo, não o que ele é, mas: que ele seja. A linguagem que o sujeito amoroso professa então (contra todas as linguagens loquazes do mundo) é uma linguagem obtusa: todo juízo é suspenso, o terror do sentido abolido. [...]

(O tenebroso inimigo do tal é a Fofoca, fábrica imunda de adjetivos. $\mathrm{E}$ o que mais se pareceria com o ser amado tal qual é seria o Texto, ao qual não posso apor nenhum adjetivo: gozo-o sem ter que decifrá-lo.) ${ }^{24}$ (BARTHES, 2003, p. 327-328, grifos do autor).

O amor não pode estar em texto, mas pode ser vivido ao modo de um, por aquele que tem no Texto (agora, novamente benfazejo) um valor ou uma paixão. Esse desvio impraticável importa, aqui, como força desviante, que contra as linguagens loquazes opera rumo a uma outra coisa, subtraída do uso corrente e 
possivelmente até do uso como operação. Se decifrar um texto é menos fazê-lo falar do que condená-lo à repetição, findar seus rumores e silêncios por uma seta de sentido límpido e único que torna prescindível a leitura, a releitura, a vivência do texto, então pronunciar quem se ama como inqualificável é, em movimento análogo, afirmar que ao menos parte do valor da relação com aquele ser ou objeto não está onde se espera.

Outro desvio apaixonado na língua é sugerido na última Figura que leremos, onde retornam a reciprocidade, $o$ presentear, o dispêndio, as relações e intervalos entre comunicar e dirigir-se a alguém, bem como outras questões já aqui visitadas:

Eu te amo

'Eu-TE-AMO. A figura não remete à declaração de amor, à confissão, mas à proferição repetida do grito de amor.

1. Passada a primeira confissão, "eu te amo" não quer dizer mais nada; essa frase nada mais faz do que retomar de um modo enigmático, tanto parece vazia, a antiga mensagem (que talvez não tenha passado por essas palavras). Repito-a sem nenhuma pertinência; ela extrapola a linguagem, divaga, onde? ${ }^{25}$ (BARTHES, 2003, p. 173, grifo do autor).

Uma das mais longas Figuras do livro, 'Eu te amo' conta dez fragmentos. No primeiro, eu-te-amo é proposto como unidade que não suportaria modificações nem reversão dos papéis interlocutórios e que, enquanto repetição, sequer teria uma mensagem ou informação a transmitir (BARTHES, 2003). Nessa série de esquivas linguísticas, eu-te-amo encontra uma categoria: a da proferição, um conceito operatório cunhado por John Austin (1962) em suas conferências sobre os atos de fala. O filósofo parte de situações bastante específicas, como promessas, sentenças jurídicas e votos de casamento, para refletir sobre situações nas quais a língua executa ações no mundo empírico (que ele denomina atos ilocucionários) e sobre o que isso implica para o conhecimento sobre o que é e como funciona a linguagem. Curiosamente, ao longo das conferências, Austin (1962) conclui que há ações implícitas em toda produção de linguagem, na medida em que haveria sempre ali a implicação "eu, falante, digo/afirmo que...”.

Os atos de fala acontecem em proferições, que são as ações vocais de dizer. Ao isolar esse termo para seu eu-te-amo, o locutor barthesiano frisa que esse bloco seria menos um ato intencional de afirmação do que uma espécie de jato verbal, algo que escapa incontrolavelmente dos lábios, sem propósito nem contexto (duas das principais condições dos atos de fala de Austin). Na mesma linha, o terceiro fragmento pergunta: "a que ordem linguística pertence pois esse ser bizarro, esse arremedo de linguagem, por demais fraseado para resultar da pulsão, por demais gritado para resultar da frase?"26 (BARTHES, 2003, p. 176). 
$\mathrm{O}$ quarto fragmento da Figura inicia com respostas indesejadas a eu-te-amo ("não acredito nem um pouco", "por que dizer?"), e chega ao obstáculo verdadeiramente lancinante: $o$ silêncio indiferente que anula a demanda amorosa e o próprio demandar, isto é, o reconhecimento do falante como dotado de existência a partir do jogo linguístico. Assim, se há nas Figuras aqui elencadas alguma insatisfação com a língua, percebida por vezes como inadequada, insuficiente ou prescindível na relação amorosa, 'Eu-te-amo' não nos deixa esquecer que é ainda pela língua que passa algo vital tanto para o contato entre apaixonado e amado quanto para a articulação do estado amoroso e daquele que ali se faz, provisória e precariamente, falante.

O sétimo fragmento, além de laudar o caráter inaugurador de eu-te-amo, que perturba as estruturas existentes e funda o Novo, concentra-se na maneira decisiva como isto se opera: "E, para cúmulo do paradoxo, esse Novo puríssimo encontra-se no fundo do mais batido estereótipo"27 (BARTHES, 2003, p. 179). É, como demonstramos alhures (OLIVEIRA; BYLAARDT, 2019) e como argumenta detalhadamente Marty (2006), o procedimento de Fragmentos como um todo: revisitar sistemas já consolidados (gêneros textuais, áreas da ciência, campos discursivos, clichês etc.) e pacientemente inscrever em suas dobras desdobramentos inauditos. Consoante, o oitavo fragmento propõe uma revisão da avaliação gregária do sofrimento amoroso, que passa de algo a ser superado a uma afirmação trágica - novamente, a recusa dos valores partilhados.

Por fim, o décimo e último fragmento da Figura declara que, absoluto e ininterpretável, eu-te-amo seria um contrassigno:

Eu-te-amo é ativo. Afirma-se como força contra outras forças. Quais? Mil forças do mundo que são, todas, forças depreciativas (a ciência, a doxa, a realidade, a razão, etc.). Ou ainda: contra a língua. [...] Como proferição, eu-te-amo não é um signo, mas joga contra os signos. [...]

Como proferição, eu-te-amo está do lado do dispêndio. Os que querem a proferição da palavra (líricos, mentirosos, errantes) são sujeitos do Dispêndio: dispendem a palavra, como se fosse impertinente (vil) que esta fosse recuperada em algum lugar; estão no limite extremo da linguagem, ali onde a própria linguagem (e que mais o faria em seu lugar?) reconhece que não tem nenhuma garantia, que trabalha sem rede. ${ }^{28}$ (BARTHES, 2003, p. 182-184, grifos do autor).

Estar no limite extremo da linguagem, operar fora de e contra as forças do mundo, alinhar-se aos líricos, aos errantes, aos mentirosos... nas Figuras em que são visitados falares amorosos, algumas propriedades, aspectos e prescrições próprios a funcionamentos ordinários ou razoáveis da língua são emperrados, suspensos, desfeitos, deslocados.

As Figuras de escritas e falares amorosos que lemos podem ter incerta confluência com a noção blanchotiana 
(2013) de inoperância, segundo a qual os resultados funcionais e/ou metrificáveis de certos escritos são nulos, neles prevalecendo um dizer que reenvia constantemente a sua própria atividade e desarticula, no vigor de sua obstinação, os determinantes que se buscam impor-lhe. Blanchot (2013) pensa sempre na literatura e, portanto, acenar a seu arcabouço conceitual é aventar alguma permeabilidade entre ela e Fragmentos. Ao rondar questões como o indizível e as limitações e excessos da linguagem ('Escrever'), a observância e extrapolar concomitantes de codificação genérica ('Carta de amor'), a indissociabilidade entre forma e ação e o dizer que a um tempo se esgota em si mesmo e ressoa como inesgotável (' $\mathrm{Eu}$ te amo'), o livro de Barthes parece-nos resvalar igualmente pelo que se convencionou chamar conteúdo naquilo que está presente também na literatura, ou que é um de seus presentes.

\section{Love and writing in Roland Barthes' A lover's discourse: fragments}

\section{Abstract}

In this essay we read some units of Roland Barthes' A lover's discourse: fragments, in attempts to map the relationships therein established between love, writing and language, which lead to key aspects of the book and of Barthes' oeuvre. We read the Fragments as part of a textual net- work (comprising also diaries and articles) and focus on the textual enunciator's ethos. We endeavor to demonstrate that, far from abandoning theoretical concepts (such as the nature of writing, subjectivity and other topics of intellectual debate over which Barthes took public stances in the years that preceded his Fragments), Barthes' more explicitly essayistic writing presupposes and acts upon those very notions. Therefore, as the book calls into question not just an object (the lover's discourse) but also its own making, the very praxis of writing comes to be conceived in different terms - as an interminable wound.

Keywords: Roland Barthes; A lover's discourse: fragments; Writing; Love.

\section{Noitas}

1 Observação: o símbolo de parágrafo § sinaliza quebra de linha no material citado.

2 La lettre d'amour. § LETTRE. La figure vise la dialectique particulière de la lettre d'amour, à la fois vide (codée) et expressive (chargée d'envie de signifier le désir). (BARTHES, 1989, p. 187).

3 je n'ai rien à te dire, sinon que ce rien, c'est à toi que je le dis (BARTHES, 1989, p. 187)

4 Le langage est une peau : je frotte mon langage contre l'autre. C'est comme si j'avais des mots en guise de doigts, ou des doigts au bout de mes mots. Mon langage tremble de désir. L'émoi vient d'un double contact : d'une parte, toute une activité de discours vient relever discrètement, indirectement, un signifié unique, qui est «je te désire », et le libère, l'alimente, le ramifie, le fait exploser [...]. Parler amoureusement, c'est dépenser sans terme, sans crise ; c'est pratiquer un rapport sans orgasme. (BARTHES, 1989, p. 87)

5 La dédicace. § DÉDiCACE. Épisode de langage qui accompagne tout cadeau amoureux, réel ou projeté, plus généralement, tout geste, effectif ou intérieur, par lequel le sujet dédie quelque chose à l'être aimé. (BARTHES, 1989, p. 89). 
6 «A ce dieu, ô Phèdre, je dédie ce discours... » On ne peut donner du langage (comment le faire passer d'une main dans l'autre?), mais on peut le dédier - puisque l'autre est un petit dieu. L'objet donné se résorbe dans le dire somptueux, solennel, de la consécration, dans le geste poétique de la dédicace [...] ; c'est le principe même de l'Hymne. Ne pouvant rien donner, je dédie la dédicace même, en quoi s'absorbe tout ce quej'ai à dire [...]. § Le chant est le supplément précieux d'un message vide, tout entier contenu dans son adresse, car ce que je donne en chantant, c'est à la fois mon corps (par ma voix) et le mutisme dont tu le frappes. (L'amour est muet, dit Novalis ; seule la poésie le fait parler.) Le chant ne veut rien dire : c'est en cela que tu entendras enfin que je te le donne; aussi inutile que le brin de laine, le caillou, tendus à sa mère par l'enfant. (BARTHES, 1989, p. 91-92)

7 Cependant, hormis le cas de l'Hymne, qui confond l'envoi et le texte lui-même, ce qui suit la dédicace (à savoir l'ouvrage lui-même) a peu de rapport avec cette dédicace. L'objet que je donne n'est plus tautologique [...], il est interprétable ; il a un sens (des sens) qui déborde de beaucoup son adresse ; j'ai beau écrire ton nom sur mon ouvrage, c'est pour « eux » qu'il a été écrit (les autres, les lecteurs). C'est donc par une fatalité de l'écriture elle-même qu'on ne peut dire d'un texte qu'il est amoureux, mais seulement, à rigueur, qu'il a été fait " amoureusement ", comme un gâteau ou une pantoufle brodée. § Et même : moins encore qu'une pantoufle ! Car la pantoufle a été faite pour ton pied [...]. Mais l'écriture, elle, ne dispose pas de cette complaisance. (BARTHES, 1989, p. 92-93)

8 Mais l'écriture, elle, ne dispose pas de cette complaisance. L'écriture est sèche, obtuse ; c'est une sorte de rouleur compresseur ; elle va, indifférente, indélicate ; elle tuerait " père, mère, amante ", plutôt que de dévier de sa fatalité (de reste, énigmatique). (BARTHES, 1989, p. 93)

9 Um exame minucioso da questão foge ao escopo deste estudo. Aos interessados, sugiro iniciar por Foucault, A ordem do discurso, de 1970; Derrida, Assinatura, acontecimento, contexto, de 1971 (no livro Margens), e Barthes: A morte do autor, de 1968, e Da obra ao texto, de 1971 (ambos no livro $O$ rumor da língua), e O Prazer do texto, de 1973. Ver também Figueiredo, E. O intertexto da "morte do autor": uma arqueologia. In: PINO; BRANDINI; BARBOSA (orgs.). Roland Barthes Plural. São Paulo: Humanitas, 2017, p. 143-157.
10 L'énonciation est cette mise en fonctionnement de la langue par un acte individuel d'utilisation. $\S[\ldots]$ c'est l'acte même de produire un énoncé et non le texte de l'énoncé qui est notre objet

11 Quelle est donc la "réalité " à laquelle se réfère je ou $t u$ ? Uniquement une "réalité de discours ", qui est chose très singulière. Je ne peut être défini qu'en termes de "locution ", non en termes d'objets, comme l'est un signe nominal. [...] je est l' " individu qui énonce la présente instance de discours contenant l'instance linguistique $j e » .[. .$.$] Ce signe est donc$ lié à l'exercice du langage et déclare le locuteur comme tel. C'est cette propriété qui fonde le discours individuel, où chaque locuteur assume pour son compte le langage entier

12 Ao final de "O aparelho formal da enunciação", Benveniste $(2005$, p. 88) especifica que a enunciação na escrita não é a mesma da fala e, portanto, requer quadro e ferramental analíticos próprios. As relações entre escrita e língua foram objeto dos últimos cursos de Benveniste no Collège de France, em 1968-69, publicados postumamente (Benveniste, É. Dernières leçons. Collège de France, 1968 et 1969. Org. e apres. Jean-Claude Coquet e Irène Fenoglio. Paris: EHESS / Gallimard / Seuil, 2012.). Para aprofundamento, ver: 1) FENOGLIO, I. "A língua e a escrita": um distanciamento teórico entre Saussure e Benveniste. Revista do GELNE, v. 19, n. Especial, 2017, p. 273298. Disponível em: <https://periodicos.ufrn. br/gelne/article/view/13588>. Acesso em: 26 abr. 2020; e 2) FLORES, V. N. A enunciação escrita em Benveniste: notas para uma precisão conceitual. D.E.L.T.A., n. 34, v. 1, 2018, p. 395417. Disponível em: <https://www.scielo.br/pdf/ delta/v34n1/1678-460X-delta-34-01-395.pdf > . Acesso em: 29 abr. 2020.

13 (Nous vérifions souvent qu'un sujet qui écrit n'a pas du tout l'écriture de son image privée : qui m'aime "pour moi-même ", ne m'aime pas pour mon écriture (et j'en souffre). C'est sans doute qu'aimer à la fois deux signifiants dans le même corps, c'est trop ! Cela ne court pas les rues. Et si par exception cela se produit, c'est la Coïncidence, le Souverain Bien.) (BARTHES, 1989, p. 93)

14 une sorte de journal intime ou de journal amoureux qui éclaire la manière dont Roland Barthes envisage la relation entre la vie, la recherche et le livre. [...] La première partie, "Chronologie ", se compose de 23 pages manuscrites rédigées entre le 20 septembre 1974 
et le $1^{\text {er }}$ février 1976 : le texte commence ainsi quelques mois avant le début du premier séminaire (janvier 1975) et se termine au début de la seconde année. Chaque double page du cahier est divisée en quatre colonnes : la première mentionne une succession de dates, la seconde, intitulée "Récit ", énumère les événements correspondants. Les personnes (l'objet amoureux, des amis, des familiers de l'auteur...) évoquées dans ces notations, qui n'excèdent pas quelques lignes, sont la plupart du temps désignées par l'initiale de leur prénom (ou de leur prénom et nom), plus rarement par leur prénom rédigé en toutes lettres. Dès le "Récit », donc, en évitant les noms propres, le diariste manifeste la même discrétion et surtout la même distance référentielle qui caractérise l'écrivain des Fragments d'un discours amoureux. Poursuivant, dans les troisième et quatrième colonnes, ce double travail de recul et de typification, Roland Barthes propose successivement pour chaque événement une « Figure » et une « Enseigne » comme il le fera dans son séminaire et plus tard dans le livre. [...] § Cela signifie très clairement que Roland Barthes, amoureux, professeur et écrivain, vivait, pour ainsi dire, simultanément un triple projet à la fois existentiel, pédagogique et littéraire [...].

15 Je ne puis donc te donner ce que j'ai cru écrire pour toi, voilà à quoi il faut me rendre : la dédicace amoureuse est impossible (BARTHES, 1989, p. 93-94)

16 L'opération dans laquelle l'autre est pris n'est pas une suscription. C'est, plus profondément, une inscription : l'autre est inscrit dans le texte, il y a fait sa trace, multiple. Si, de ce livre, tu n'étais que le dédicataire, tu ne sortirais pas de ta dure condition d'objet (aimé) - de dieu ; mais ta présence dans le texte, par là même que tu y es méconnaissable, n'est pas celle d'une figure analogique, d'un fétiche, c'est celle d'une force, qui n'est pas, dès lors, de tout repos. (BARTHES, 1989, p. 94)

17 Inexprimable amour § ÉCRIRE. Leurres, débats et impasses auxquels donne lieu le désir d' " exprimer» le sentiment amoureux dans une " création " (notamment d'écriture). (BARTHES, 1989, p. 113)

18 Para estudos mais detalhados da questão, ver Perrone-Moisés (2012a) e Oliveira e Bylaardt (2019).

19 Je suis à la fois trop grand e trop faible pur l'écriture : je suis à côté d'elle, qui est toujours serrée, violente, indifférente au moi enfantin qui la sollicite. L'amour a certes partie liée avec mon langage (qui l'entretient), mais il ne peut se loger dans mon écriture. (BARTHES, 1989, p. 114)

20 Quel est ce moi qui s'écrirait? Au fur et à mesure qu'il entrerait dans l'écriture, l'écriture le dégonflerait, le rendrait vain ; il se produirait une dégradation progressive, dans laquelle l'image de l'autre serait, elle aussi, peu à peu entraînée (écrire sur quelque chose, c'est le périmer), un dégout dont la conclusion ne pourrait être que : à quoi bon? Ce qui bloque l'écriture amoureuse, c'est l'illusion d'expressivité : écrivain, ou me pensant tel, je continue à me tromper sur les effets du langage [...]. Il faudrait que quelqu'un m'apprenne qu'on le peut écrire sans faire le deuil de sa "sincérité » (toujours le mythe d'Orphée : ne pas se retourner). (BARTHES, 1989, p. 114-115)

21 Savoir qu'on n'écrit pas pour l'autre, savoir que ces choses que je vais écrire ne me feront jamais aimer de qui j'aime, savoir que l'écriture ne compense rien, ne sublime rien, qu'elle est précisément là où tu n'es pas - c'est le commencement de l'écriture. (BARTHES, 1989, p. 116)

22 Comblements : on ne les dit pas - en sorte que, faussement, la relation amoureuse paraît se réduire à une longue plainte. [...] le moi ne discourt que blessé ; lorsque je suis comblé ou me souviens de l'avoir été, le langage me paraît pusillanime : je suis transporté, hors du langage, c'est-à-dire hors du médiocre, hors du général [...]. (BARTHES, 1989, p. 66)

23 En réalité, peu m'importent mes chances d'être réellement comblé (je veux bien qu'elles soient nulles). Seule brille, indestructible, la volonté de comblement. Par cette volonté, je dérive : je forme en moi l'utopie d'un sujet soustrait au refoulement : je suis déjà ce sujet. (BARTHES, 1989 , p. 66)

${ }_{24}$ J'accède alors (fugitivement) à un langage sans adjectifs. J'aime l'autre non selon ses qualités (comptabilisées), mais selon son existence ; par un mouvement que vous pouvez bien dire mystique, j'aime, non ce qu'il est, mais : qu'il est. Le langage dont le sujet amoureux proteste alors (contre tous les langages déliés du monde) est un langage obtus : tout jugement est suspendu, la terreur du sens est abolie. § (L'ennemi noir du tel, c'est le Potin, fabrique immonde d'adjectifs. Et ce qui ressemblerait le mieux à l'être aimé tel qu'il est, ce serait le Texte, sur lequel je ne puis apposer aucun adjectif : dont 
je jouis sans avoir à le déchiffrer). (BARTHES, 1989 , p. 262-263)

25 Je t'aime $\S$ Je-t-aime. La figure ne réfère pas à la déclaration d'amour, à l'aveu, mais à la profération répétée du cri d'amour. $§ 1$. Passé le premier aveu, "je t'aime » ne veut plus rien dire ; il ne fait que reprendre d'une façon énigmatique, tant elle parait vide, l'ancien message (qui peut-être n'est pas passé par ces mots). Je le répète hors de toute pertinence; il sort du langage, il divague, où ? (BARTHES, 2003, p. 175)

26 À quel ordre linguistique appartient donc cet être bizarre, cette feinte de langage, trop phrasée pour relever de la pulsion, trop criée pour relever de la phrase ? (BARTHES, 1989, p. 177)

27 Et, pour comble de paradoxe, ce Nouveau tout pur est au bout du plus éculé des stéréotypes (BARTHES, 1989, p. 179)

28 Je-t-aime est actif. Il s'affirme comme force contre d'autres forces. Lesquelles? Mille forces du monde, qui sont, toutes, forces dépréciatives (la science, la doxa, la réalité, la raison, etc. $\mathrm{Ou}$ encore : contre la langue. [...] Comme profération, je-t-aime n'est pas un signe, mais joue contre les signes. [...] § Comme profération, je-t-aime est du côté de la dépense. Ceux qui veulent la profération du mot (lyriques, menteurs, errants) sont sujets de de la Dépense : ils dépensent le mot, comme s'il était impertinent (vil) qu'il fût quelque part récupéré ; ils sont à la limite extrême du langage, là où le langage lui-même (et qui d'autre le ferait à sa place ?) reconnaît qu'il est sans garantie, travaille sans filet. (BARTHES, 1989, p. 182-183)

\section{Referências}

AUSTIN, J. L. How to do things with words. The William James Lectures delivered at Harvard University in 1955. Oxford: Oxford University Press, 1962.

BARTHES, R. Fragments d'un discours amoureux. Paris: Seuil, 1989.

BARTHES, R. Vita Nova. In: Euvres Complètes. Paris: Seuil, 2002. v. V, p. 1008-1014.

BARTHES, R. Fragmentos de um Discurso Amoroso. Trad. Márcia Valéria Martinez de Aguiar. São Paulo: Martins Fontes, 2003.
BARTHES, R. O grau zero da escrita, seguido de Novos ensaios críticos. Trad. Mario Laranjeira. São Paulo: Martins Fontes, 2004.

BARTHES, R. Le Discours Amoureux. Séminaire à l'École pratique des hautes études 1974-1976. Suivi de Fragments d'un discours amoureux: inédits. Paris: Seuil, 2007.

BARTHES, R. Diário de luto. 26 de outubro 1977 - 17 de setembro de 1979. Trad. Leyla Perrone-Moisés. São Paulo: Martins Fontes, 2011.

BARTHES, R. Da obra ao texto. In: $O$ rumor da língua. Trad. Mário Laranjeira. São Paulo: WMF Martins Fontes, 2012a. p. 65-75.

BARTHES, R. Escrever, verbo intransitivo? In: O rumor da língua. Trad. M. Laranjeira; Andréa S. M. Silva. 3. ed. São Paulo: WMF Martins Fontes, 2012b. p. 13-25.

BARTHES, R. Album. Inédits, correspondances et varia. Paris: Seuil, 2015.

BELLOCCHIO, C. M. Uma visão sutil do mundo: Escritura, enunciação e variação em Roland Barthes. 2017. Tese (Doutorado em Letras) Faculdade de Filosofia, Letras e Ciências Humanas - Universidade de São Paulo, São Paulo, 2017.

BENVENISTE, É. Problèmes de linguistique générale, 2. Paris: Gallimard, 2005.

BENVENISTE, É. Problèmes de linguistique générale, 1. Paris: Gallimard, 2014.

BLANCHOT, M. L'espace littéraire. Paris: Gallimard, 1962.

BLANCHOT, M. Kafka e a literatura. In: $A$ parte do fogo. Trad. Ana Maria Scherer. Rio de Janeiro: Rocco, 1997. p. 19-33.

BLANCHOT, M. O desaparecimento da literatura. In: $O$ livro por vir. Trad. Leyla Perrone-Moisés. 2. ed. São Paulo: WMF Martins Fontes, 2013. p. 285-295.

COSTE, C. Préface. In: BARTHES, R. Le discours amoureux. Séminaire à l'École pratique des hautes études 1974-1976, suivi de 
Fragments d'un discours amoureux: inédits. Paris: Seuil, 2007, p. 19-45.

COSTE, C. De l'École au Collège. In: Roland Barthes ou l'art du détour. Paris: Hermann, 2016. p. 29-54.

DERRIDA, J. De la Grammatologie. Paris: Les Éditions de Minuit, 1967.

DERRIDA, J. Morada Maurice Blanchot. Trad. Silvina R. Lopes. Lisboa: Vendaval, 2004.

FLORES, V. N.; ENDRUWEIT, M. L. A noção de discurso na teoria enunciativa de Émile Benveniste. Moara, n. 38, Estudos Linguísticos, p. 196-208, 2012. Disponível em: $<$ https://periodicos.ufpa.br/index.php/moara/ article/view/1280>. Acesso em: 04 fev. 2020.

LOPES, S. R. A legitimação em literatura. Lisboa: Cosmos, 1994.

MARTY, É. Roland Barthes, le métier d'écrire. Paris: Seuil, 2006.

OLIVEIRA, P. P. L. de. Inconfessadamente ditoso: trânsitos do eu nas escritas de Roland Barthes e de Ana Cristina Cesar. 2015. 161f. Dissertação (Mestrado em Letras) - Faculdade de Filosofia, Letras e Ciências Humanas, Universidade de São Paulo, São Paulo, 2015. DOI http://dx.doi.org/10.11606/D.8.2015.tde10122015-161547.

OLIVEIRA, P. P. L. de; BYLAARDT, C. O. O estranho murmúrio de Fragmentos de um Discurso Amoroso. Estudos Linguísticos e Literários, Salvador, p. 46-64, n. 62, jan.-jun. 2019. Disponível em: https://portalseer.ufba.br/index.php/estudos/article/ view/27675. DOI http://dx.doi.org/10.9771/ ell.v0i62.27675. Acesso em: 27 maio 2021.

PERRONE-MOISÉS, L. Discurso amoroso e discurso de poder. In: Com Roland Barthes. São Paulo: WMF Martins Fontes, 2012a. p. 89-94.

PERRONE-MOISÉS, L. O semiólogo apaixonado. In: Com Roland Barthes. São Paulo: WMF Martins Fontes, 2012b. p. 95-99.
PINO, C. A. Nem sempre fracassamos ao falar do que amamos. O discurso e a narrativa amorosa de Roland Barthes. Remate de Males, v. 31, n. 1-2, p. 211-226, 2011. Disponível em: $<$ https://periodicos.sbu.unicamp.br/ojs/index. $\mathrm{php} / \mathrm{remate} /$ article/view/8636230>. Acesso em: 30 jan. 2020.

PINO, C. A. Roland Barthes: a aventura do romance. Rio de Janeiro: Sette Letras, 2015.

ROGER, P. Roland Barthes, roman. Paris: Grasset \& Fasquelle, 1986. 